\title{
A survey of institutional influenza vaccination in Switzerland
}

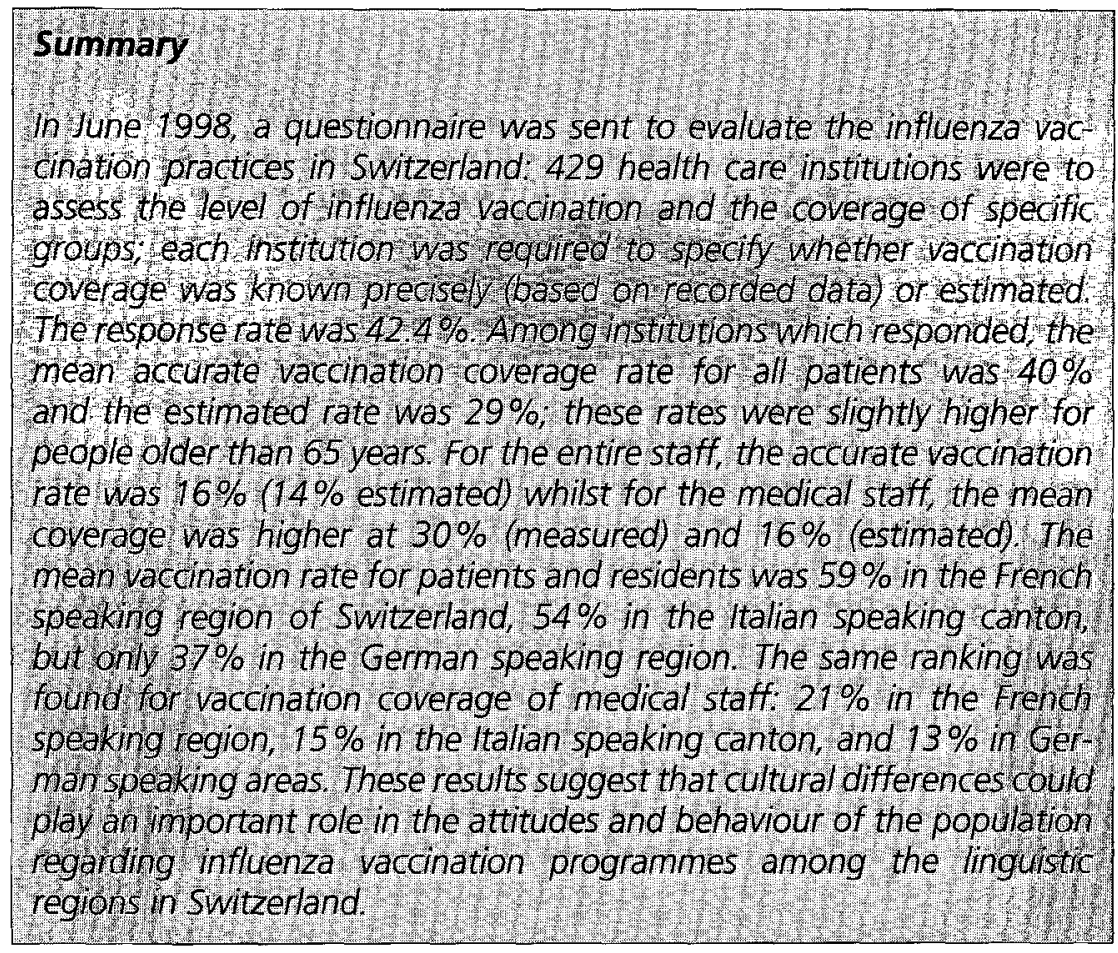

In Switzerland, the mortality rate due to influenza infection has been estimated at more than 1000 deaths a year based on death certificates $^{1,2}$. The average mortality rate due to influenza is underreported and it might be assumed to be four times higher than the official death declarations [Claude Hannoun, personal communication] as the death certificates document only the major causes of death and not any underlying conditions ${ }^{3}$.

Influenza vaccination has been shown to be efficacious and efficient in preventing infection in the population, providing considerable financial savings due to fewer episodes of upper respiratory tract infection and fewer visits to the physician. For high risk groups, the vaccination reduces the frequency of hospitalizations and the mortality $^{4-6}$. Nevertheless, there is no uniformity in the definitions of risk groups and recommendations on who should receive the vaccine vary between different countries ${ }^{7}$.

Within Western Europe, there are differences in the recommendations for the elderly?; in Belgium it is recommended for people over 60 years, in Switzerland for those over 65 years, in France for those more than 70 years of age whereas the United Kingdom decided for the first time in 1998 to recommend vaccination for elderly people who are more than 75 years old ${ }^{8}$. In all countries there are recommendations to vaccinate persons at high risk for influenza such as those with chronic heart, lung or kidney disease, diabetes or other serious illnesses ${ }^{9}$.

Within Western Europe, Switzerland has one of the lowest influenza vaccination coverage rates with an estimated 75 doses of vaccine distributed per 1000 total population in 1997, and 100 doses in 1998. This figure does not mean that all doses of vaccine distributed are actually administered, nor does it mean that all doses given are received by persons for whom vaccination is specifically recommended.

The Swiss Federal Office of Public Health (SFOPH) publishes annual 
recommendations on the vaccination against influenza ${ }^{1}$. However, the health authorities of the 23 cantons are free to organize and promote vaccination programmes locally. This leads to an inconsistent promotion within the country. In 1997/98, influenza vaccination was recommended for individuals older than 65 years, for adults and children with cardiac or pulmonary pathologies, for residents of homes and health institutions, and for patients with chronic diseases; for all persons in these groups the medical insurance companies guarantee reimbursement for the cost of vaccination. The medical staff and personnel of health care institutions as well as family and contacts of individuals at risk are also recommended for vaccination but no reimbursement is provided by the insurance companies.

This study was conducted in June 1998 to collect information on influenza vaccination coverage and promotion practices. Another objective was to discover which promotional support would be most effective in encouraging the application of influenza vaccination within health care institutions (not shown here).

\section{Material and Methods}

\section{Institutions}

In June 1998 a questionnaire was sent to 429 Swiss health care institutions. They were selected through a private association which provides statistical and accounting services to the major health care providers in the country. All members of this association were contacted for the survey. This systematic sampling included university and general hospitals $(51 \%)$, maternity and children's hospitals $(8 \%)$, rehabilitation clinics $(10 \%)$, retirement and nursing homes $(21 \%)$ and psychiatric clinics $(10 \%)$ (Table 1 ). These enrolled institutions account for $15 \%(429 / 2882)$ of all health care institutions in Switzerland.

\section{Questionnaire}

The questionnaire was sent to each institution itself, not to a specific addressee. It was first written in French and then translated into German and Italian. Overall, 299 institutions received the questionnaire in German, 101 in French and 29 in Italian. The analysis separates the data collected in the three lin- guistic regions. The cut-off time for reply was one month, no reminders were issued.

The first part of the questionnaire concerned the level of influenza vaccination within the institution with emphasis on the vaccination coverage within specified groups (total residents/patients; patients older than 65 years; all staff, including paramedical and administrative as well as technical staff, and medical staff alone). The respondent was requested to specify whether vaccination coverage had been measured using records of doses administered, or whether a less precise method of estimation had been used.

The second part of the questionnaire dealt with specific actions to promote influenza vaccination within an institution. The respondent's opinions on the most useful means and support required to promote influenza vaccination in case of a national campaign, and who should play the principal role in a vaccination programme were also requested (results not shown here). The questionnaire was pilottested on a small group of professionals selected from public and private health institutions.

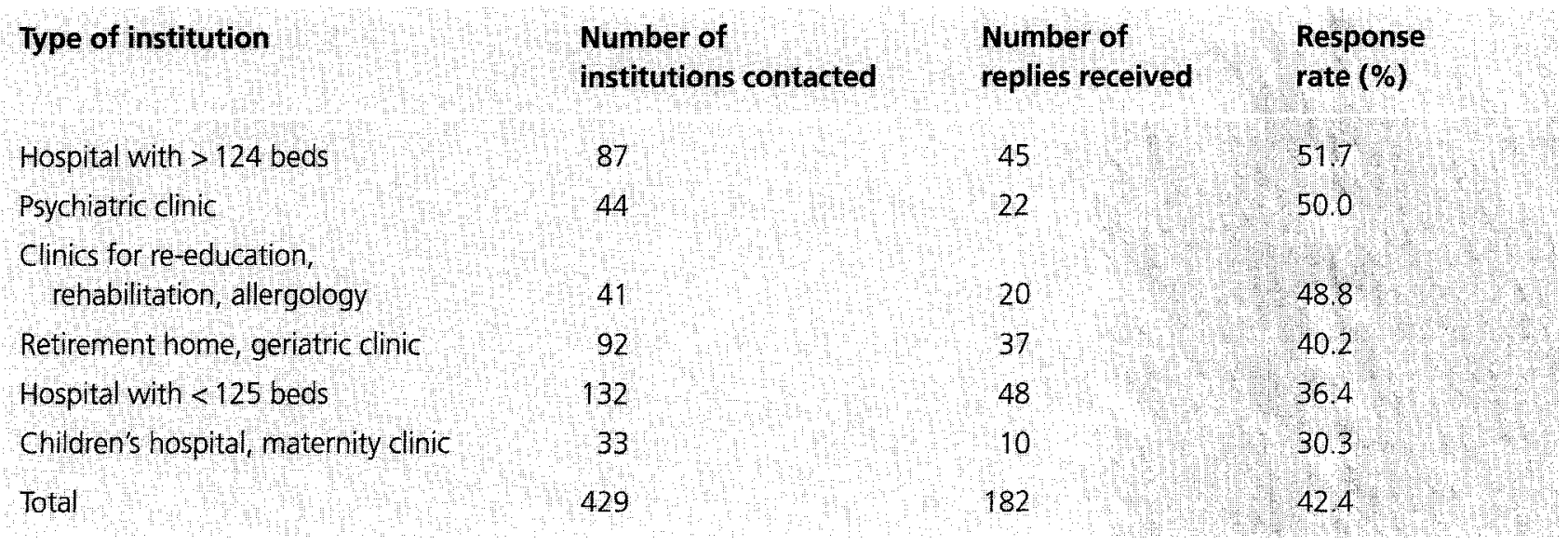

Table 1. Health institutions involved in the survey and response rates, Switzerland, 1998 (ranked by response rate). 


\section{Statistics}

The analysis of data was performed at the Institute of Social and Preventive Medicine in Geneva using SPSS software version 6.0 for Windows. Data is summarized using means and ranges. Means were calculated without weighting by size of institution.

\section{Results}

$429(14.9 \%)$ of the existing 2882 Swiss health care institutions were included in this survey. The response rate was $42.4 \%(182 / 429)$ and varied according to the type of institution (Table 1).

Respondents from all institutions were asked to provide the precise rate of vaccination coverage of the different risk groups, if known. Otherwise, they were asked to provide an estimate or to state that no reply was possible (Table 2). This information was obtained for each of the four groups: all patients/residents; elderly residents; all institution staff; and medical staff. Overall, $40 \%$ of all institutions were unable to provide any data on the vaccination rates of their patients, residents or employees.

The precise vaccination coverage rates for all patients and residents ranged from 0 to $100 \%$ with a mean of $40 \%$; where the rate was estimated the mean was $29 \%$ (Table 3 ). These rates were slightly higher for elderly people ( $47 \%$ known and $37 \%$ estimated coverage). With regard to the entire institution staff, the mean precisely known immunization rate was $16 \%$ $(0-100 \%)$ but only $14 \%(0-80 \%)$ where estimated. These numbers were slightly higher for medical staff, where $30 \%(0-100 \%)$ were known to have been vaccinated against influenza and $16 \%(0$ $80 \%$ ) were estimated to have been vaccinated.

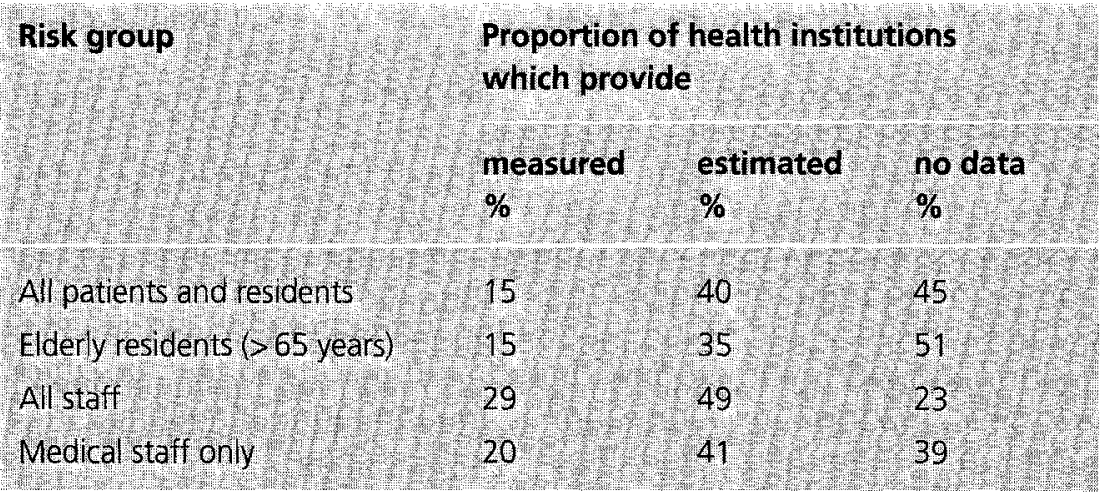

Table 2. Proportion of health institutions providing measured, estimated or no data on vaccination coverage of risk groups $(N=182)$, Switzerland, 1998.



Table 3. Measured and estimated vaccination coverage rate (mean and range) of risk groups, Switzerland, 1998.

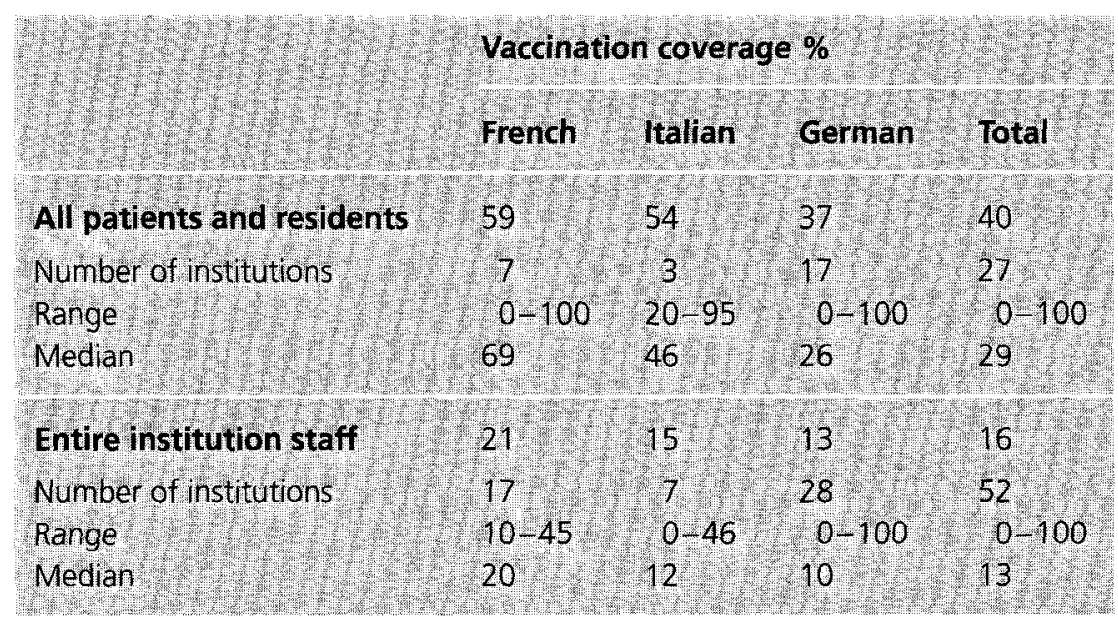

Table 4. Vaccination coverage (mean and range) for institution returning measured data, for two risk groups, according to the linguistic regions of Switzerland, 1998. 
The responses were also evaluated according to the three major linguistic regions of Switzerland (Table 4). The mean vaccination rate for patients and residents was highest in the French speaking region $(59 \%)$, and almost as high as in the Italian speaking canton (54\%), whereas in the German speaking region it was lower $(37 \%)$. Similar findings were obtained for vaccination coverage of the medical staff: $21 \%$ in the French speaking region, $15 \%$ in the Italian speaking canton and $13 \%$ in the German speaking region.

\section{Discussion}

The relatively low response rate of $42.4 \%$ may be explained by the facts that no reminder was sent, questionnaires were sent outside the vaccination period, shortly before a holiday period, and without a specific addressee. No information is available concerning the non-respondents. The lower response rates in the children's and mothercare clinics may be due to the fact that the management of such institutions has little concern about this vaccination ${ }^{1,9}$. The high response rates in large hospitals and psychiatric clinics may reflect a concern with influenza vaccination due to the presence in these institutions of patients of all risk groups.

The mean estimated rates for vaccination coverage were generally lower than the precisely known rates. The differences varied between $14 \%$ for the medical staff, $11 \%$ for the residents and $10 \%$ for the elderly; but this was not true for the entire staff where the mean estimated rate was only $2 \%$ lower than the measured rates (Table 3). This difference may be related to a reputation of uselessness and lack of efficiency of the influenza vaccination within the medical institutional environment. The highest precisely known mean vaccination rates were found for the elderly $(47 \%)$ and the residentspatients $(40 \%)$. The SFOPH recommends vaccination for these groups, while the staff is eligible for vaccination but not considered a risk group. The cost of the vaccine is not reimbursed by the medical insurance for the employees of health institutions, a fact which might contribute to the underestimation of the coverage as well as the low vaccination rate. Nevertheless, these rates are low in comparison with studies in other countries. Nichol found that immunization rates in the United States among high risk patients can be increased from $58 \%$ to $84 \%$ with a good vaccination program ${ }^{10}$. In comparison, vaccination coverage for the elderly with high risk conditions discharged from hospitals is reported to be at $68 \%$ in the United Kingdom ${ }^{11}$ and about $70 \%$ in France ${ }^{12}$.

For patients and residents, the mean rates were very low, particularly as it has been shown that the vaccination of health care workers had important beneficial effects on patient mortality and frequency of influenza-like illness ${ }^{13}$. Other studies confirmed that the vaccination of health workers reduces febrile respiratory illness and reported days of work absence ${ }^{14,15}$.

With regard to the staff, either all employees or only medical personnel, the measured and estimated rates for influenza vaccination coverage were much lower than for the other groups, potentially reflecting little interest in protecting the staff or a possible resistance toward this preventive measure.

The results also demonstrate that the perception of public health measures differs between the three linguistic regions. The differences among the three regions appeared strongly also in the Swiss Health Survey. For the total population the number of persons vaccinated within the last two years preceding the survey (vaccinated in 1996 and/or 1997) are $17.8 \%$ in the French speaking area, $11.2 \%$ in the Italian speaking canton, and $9.7 \%$ for German speaking Switzerland $^{16}$. The 1996 coverage in Switzerland is $6.1 \%$, for comparison in the neighbouring countries based on the number of sold doses, the rates are $15.0 \%$ for Italy, $13.4 \%$ for France, $9.2 \%$ for Germany and $6.1 \%$ for Austria [David Fedson, Fred Ambrosch, personal communication]. One can suggest that this may be due to a tendency for a similar identity as well as cultural influence from the neighbouring country speaking the same language. France has been very active in promoting influenza vaccination for nearly 20 years and the impact of this media campaign has been felt throughout the French speaking part of Switzerland. Germany and Austria show a low vaccination coverage, and some German speaking cantons are the home for antivaccination activist movements; especially the Swiss Germans seem to favour more natural preventive measures and tend to reject immunisations. The coverage rate for the Italian speaking canton cannot be compared with the Italian national rate, unfortunately specific data for the Italian autonomous regions bordering Ticino are not available.

\section{Conclusion}

This study has shown that in Switzerland, where no national influenza vaccination programme exists, knowledge of health institutions on vaccination rates either of their patients or their employees is sparse and uncertain. When precisely known vaccination coverage mean rates for the patients-residents, the elderly and the medical staff are higher than the rates given when they are estimated. Overall, Swiss immunization rates are generally well below those of other European countries and the 
United States. The SFOPH recommends the vaccination for specific risk groups but each canton is free to decide whether to organize the promotion locally. Cultural differences appear to play an important role with regard to the perception of influenza vaccination programmes and their promotion and monitoring, as shown by the differences in immunization rates in the French, Italian and German speaking regions. The question arises whether vaccination programmes should continue to be delegated to the cantons but with an increased assistance and support by the federal health authorities, or be better conducted entirely by the SFOPH with a promotion adapted to the local sensibilities and cultural identities within the country. Both options would increase protection against influenza and achieve a better cultural balance in the promotion of this important preventive intervention.

\section{References}

1 Swiss Federal Office of Public Health. Recommandations pour la prévention de la grippe. Diagnostic et prévention. Maladies infectieuses. Supplementum XIII. August 1996. Bern: SFOPH, 1996.

2 Egger $M$, Jennings $S$, Spuhler $T$, Zimmermann HP, Paccaud F, Somaini $B$. Sterblichkeit während Grippeepidemien in der Schweiz 1969-1985. Schweiz Med Wochenschr 1989; 119: 434-9.

3 Carrat $F$, Valleron $A-J$. Influenza mortality among the elderly in France, 1980-90: how many deaths may have been avoided through vaccination? J Epidemiol Community Health 1995; 49: 419-25.

4 Nichol KL, Margolis KL, Wuorenma J, Von Sternberg $T$. The efficacy and cost effectiveness of vaccination against influenza among elder-

\section{Zusammenfassung}

\section{Eine Befragung zur Grippeimpfung in Institutionen des Pflegebereichs in der Schweiz}

Im uni 1998 fuhrten wir eine studie zur Grippemplung der Schwelz durdh 429 medizinische institutionen erhielten einen fragebogen um. die Rate der Grippeimpfung unter Einbeziehung spezifischer Risikogruppen zu evaluieren. Jede Institution musste angeben, ob die Impfrate genau bekannt (aufgrund der existierenden Daten) oder geschatzt wan Die Antwortrate lag bei $42,4 \%$. Die generelle Imofrate in den befragten Institutionen lag für alle Patienten bei $40 \%$ und die geschätzte Rate ber 29\%, diese impfraten waren etwas höher fur Personen uber 65 lahre. Was das gesamte Personal Jeder Institution betrifft lag die Implrate bel $16 \%$, wahrend die imptrate für das Medzinische und paramedzhische Personal bei $30 \% \mathrm{lag}$. In franzásisch sprechenden Regionen der schweiz lag die Impfrate fur die Patienten bel $59 \%$, in itallenisch sprechenden Regionen bei $54 \%$, in deutschsprachigen Regionen jedoch bei nur $37 \%$. Die gleichen regionalen Uhterschiede fanden sich auch bel den Impf raten des medizinischen und paramedizinischen Personals. Aurgrund dieser Ergebnisse kann man annehmen, dass kulturelle Unterschiéde in den Sprachregionen eine wichtige Rolle spielen bezüglich des Verhaitens der bevolkering gegenuber der Gripemprung:

\section{Résumé \\ Une enquête sur la vaccination contre la grippe en suisse dans les institutions de soins}

En Juin 1998, un questionnaire est envoyé pour évaluer les pratiques de vaccination contre la grippe en Suisse: 429 établissements de soins ont evalue le taux de vaccination contre la gripoe de certains groupes. Chaque institution devait specifier si le taux était précisement connu. (basé sur les données existantes) ou estimé. Le taux de réponse est de 42.4\%. La couverture vaconale moyenne connue des patients-résidents est de $40 \%$, alors que l'estimation est à $29 \%$; ces taux sont légèrement superieurs pour les personnes de plus de 65 ans. Pour I'ensemble du personnel, le taux de vaccination connu s'élève à $16 \%$ (estimation $14 \%$; pour le personnel médical, la couverture mesurée est de $30 \%$ et l'estimation à $16 \%$ Le taux moyen de couverture des patients-résidents est de $59 \%$ en Romandie, $54 \%$ au Tessin, $37 \%$ en suisse alemanique. (es différences se retrouvent dans le taux de couverture du personnel mé dical $21 \%$ en Suisse romande, $15 \%$ en Suisse italienne, $13 \%$ en Suisse alémanique. Ces résultats suggèrent que les différences culturelles inhérentes aux régions linguistiques peuvent jouer un rôle important dans les attitudes et comportements de la population face aux programmes de vaccination contre la grippe. 
ly persons living in the community. N Engl J Med 1994; 331: 778-84.

5 Fedson DS, Wajda A, Nicol P, Hammond GW, Kaiser DL, Roos LL. Clinical effectiveness of influenza vaccination in Manitoba. JAMA 1993; 270: 1956-61.

6 Puig-Barberà I, Marquez-Calderòn $S$, Masoliver-Fores $A$, et al. Reduction in hospital admissions for pneumonia in non-institutionalised elderly people as a result of influenza vaccination: a case-control study in Spain. J Epidemiol Community Health 1997; 51: 526-30.

7 Fedson DS, Hirota $Y$, Shin $H-K$, et al. Influenza vaccination in 22 developed countries: an update to 1995. Vaccine 1997; 15: 1506-11.

8 PHLS, Communicable Disease Surveillance Centre. Influenza immunisation to include all those aged 75 years and over. CDR 1998; 8 : 297-300.

9 Centers for Disease Control and Prevention. Prevention and control of influenza. Recommendations of the Advisory Committee on immunization practices. MMWR Morb Mortal Wkly Rep 1997; 46(RR-9): $1-21$.
10 Nichol $K L$. Ten-year durability and success of an organized program to increase influenza and pneumococcal vaccination rates among high-risk adults. Am J Med 1998; 105: 385-92.

11 Willis $J$, Watkins $J$. Influenza vaccination policy and high risk subjects. Targeting and delivery should remain in general practice. BMJ 1998; 317: 349 .

12 Hannoun $C$. Le vaccin antigrippal d'aujourd'hui et demain. Virologie 1997; 1: 121-31.

13 Potter J, Stott DJ, Roberts MA, et al. Influenza vaccination of health care workers in long-term-care hospitals reduces the mortality of elderly patients. J Infect Dis 1997; 175: 1-6.

14 Wilde J, McMillan J, Serwint J, Butta J, O'Riordan MA, Steinhoff, $M$. Effectiveness of influenza vaccine in health care profesionals. A randomized trial. JAMA 1999; 281: 908-13.

15 Nichol KL, Lind A, Margolis KL, et al. The effectiveness of vaccination against influenza in healthy, working adults. N Engl J Med 1995; 333: 889-93.
16 Swiss Federal Office of Statistics. Swiss Health Survey. Neuchâtel: SFOS 1999.

\section{Acknowledgements}

The study was carried out on behalf of the Institute of Social and Preventive Medicine of Geneva and funded by the Swiss Federal Office of Public Health. The author thanks Dr Hans C. Matter from the Swiss Federal Office of Public Health, Dr Beate Heym and Dr James Robertson for critical reading of the manuscript, and Dr Dennis Chanter from Quintiles for assistance with the statistics.

\section{Address for correspondence}

Catherine Ammon, MPH

Swiss Federal Office of Public Health

Viral Diseases and Sentinella Systems P.O. Box

CH-3003 Bern

Tel.: +41313231339

Fax: +41313238795

catherine.ammon@bag.admin.ch 